\title{
Unravelling the risk factors that underlie oral and oropharyngeal surgery in elderly
}

\author{
Chiarire i fattori di rischio che sottendono la chirurgia del cavo orale \\ e dell'orofaringe negli anziani
}

\author{
G. MOLTENI ${ }^{1}$, S. VALERINI ${ }^{1}$, M. ALICANDRI-CIUFELLI ${ }^{1}$, A.E. SPRIO ${ }^{2}$, E. CROSETTI ${ }^{3}$, G.N. BERTA², \\ L. PRESUTTI', G. SUCCO ${ }^{3}$ \\ ${ }^{1}$ Otorhinolaryngology Service, AOUI Verona Hospital, University of Verona, Department of Head and Neck Surgery, \\ Verona, Italy; ${ }^{2}$ Department of Clinical and Biological Sciences, University of Turin, Italy; ${ }^{3}$ Head and Neck Oncology \\ Service, Oncology Department, University of Turin, IRCCS FPO Candiolo Cancer Institute, Italy
}

\section{SUMMARY}

Oral squamous cell carcinoma (OSCC) diagnoses in elderly patients are expected to double in the next 20 years. Current guidelines suggest surgery as a preferred approach, but elderly patients are hardly considered suitable to challenging surgical treatments. Using a multicentric retrospective analysis, we evaluated the outcomes of 99 patients affected by OSCC and aged at least 70, who underwent to either transoral procedures (TP), open neck resection without (OR) or with reconstruction (ORR). In our cohort, overall survival was significantly hampered by concomitant diseases and postsurgical complications, whose development is driven by the former. Thus, our findings support the growing acceptance that chronological age alone should not be a sufficient contraindication for aggressive surgery in the treatment of OSCC. However, elderly patients affected by OSCC are undoubtedly delicate surgical candidates and accurate selection prior to surgery with curative intent is mandatory.

KEY WORDS: Oral cancer • Elderly • Reconstructive surgery • Complications • Free flap • Quality of life

\section{RIASSUNTO}

Nei prossimi vent'anni è previsto che il numero di diagnosi di carcinoma del cavo orale nel paziente anziano raddoppi. L'approccio chirurgico resta la terapia d'elezione sebbene sia dibattuto se esso possa essere praticabile negli anziani anche nei casi più demolitivi. Attraverso un'analisi retrospettiva multicentrica, abbiamo valutato 99 pazienti ultra-settantenni affetti da carcinoma della cavità orale sottoposti a chirurgia transorale, o resezione open con o senza ricostruzione. Nella nostra coorte, la sopravvivenza dei pazienti è stata negativamente influenzata dalla presenza di comorbidità e dallo sviluppo di complicanze post-operatorie. Inoltre, la comparsa di tali complicanze è stata posta in diretta correlazione con la presenza di una o più patologie concomitanti nel quadro clinico del paziente. Tuttavia, sebbene il paziente anziano sia un candidato delicato per approccio chirurgico ed un'accurata selezione sia quindi necessaria, $i$ nostri risultati suggeriscono che l'età anagrafica non debba essere considerata una controindicazione sufficiente ad escludere a priori pazienti anziani candidati a trattamento chirurgico.

PAROLE CHIAVE: Cancro del cavo orale $\bullet$ Anziani $\bullet$ Chirurgia ricostruttiva $\bullet$ Complicanze $\bullet$ Lembi liberi $\bullet$ Qualità di vita

Cite this article as: Acta Otorhinolaryngol Ital 2018;38:409-416. http://dx.doi.org/10.14639/0392-100X-1507

(C) Società Italiana di Otorinolaringologia e Chirurgia Cervico-Facciale

\section{Introduction}

Alarming epidemiological data have been reported for many tumour histotypes, particularly for head and neck squamous cell carcinomas (HNSCC), including oral (OSCC). Indeed, an increase in diagnosis from the present $\sim 300,000$ cases worldwide to $\sim 500,000$ is expected within $2035(+65 \%)$. More worryingly, the $\sim 115,000$ OSCC currently diagnosed in elderly patients $(\geq 65$ years old) are expected to double (about $+104 \%$ ) in the next 20 years, while those in younger will "only" increase by about $40 \%{ }^{1}$.

Current guidelines for treatment of OSCC require surgery as the preferred approach, whereas they suggest radiotherapy or chemoradiotherapy for advanced-stage cancer in the presence of adverse features ${ }^{2}$. Photodynamic therapy may be otherwise considered as an approach for the management of previously-treated patients or for those 
who are not suitable for conventional therapies. Therefore, complex reconstructive surgeries have been used more and more frequently in the last two decades to improve the posttreatment quality of life. However, this trend determines an extension of surgical times, as well as a general need to carefully select patients, which is based on the most serious comorbidity to reduce complications and overall costs. In this scenario, elderly patients are not considered to be good candidates to undergo more challenging treatments, e.g. highly invasive resective/reconstructive surgery and complex chemotherapy schedule ${ }^{3}$.

To provide surgeons with a model to choose the most appropriate treatment options, we retrospectively analysed 99 patients aged at least 70, suffering for OSCC, and treated with radical intent with 3 different types of surgery: transoral procedures (TP), open neck resection without reconstruction (OR) and open neck resection with reconstruction (ORR). Major outcomes as well as the incidence of posttreatment complications were evaluated, whereas predictive factors involved in their occurrence were identified.

\section{Materials and methods}

\section{Patients and surgery}

After informed consent was obtained, all patients underwent surgery for OSCC at the Policlinico Hospital in Modena or at the Martini - San Luigi Gonzaga Hospitals of Turin between January 1, 2001, and December 31, 2012. Data collection from the medical charts included demographic information such as age and sex, TNM staging, tumour site and subsite, tumour histology, physical status according to the American Society of Anesthesiologists (ASA) ${ }^{4}$, age at the surgical time, type of surgery and neck dissection, type of reconstruction, duration of surgery, duration of hospitalisation (including days in intensive care unit, ICU), comorbidities and perioperative complications. The assessed comorbidities were diabetes mellitus, hypertension, chronic obstructive pulmonary disease (COPD), cardiac diseases (including chronic heart failure, arrhythmia and coronary artery disease), hepatic, metabolic and cerebrovascular diseases.

In the present retrospective study, age at the time of surgery $\geq 70$ years ${ }^{5-7}$, histological diagnosis of OSCC and surgical treatment with curative intent (as single modality or as part of a multimodality approach) were considered as inclusion criteria.

The chart data of 99 patients were retrieved. The choice of the treatment was based on tumour stage and site, as well as comorbidities, but non-considering chronological age as a discriminatory factor. Procedures were classifiable as tran-
Table I. Characteristics of the 99 elderly patients undergoing head and neck surgery according to age, sex and pathological status.

\begin{tabular}{|c|c|c|c|c|c|c|}
\hline & & & & & & $\begin{array}{l}\text { No. of patients } \\
(\%)\end{array}$ \\
\hline \multicolumn{7}{|l|}{ Age, y } \\
\hline Mean & & & & & & $77.0 \pm 5.6$ \\
\hline Range & & & & & & $70-93$ \\
\hline $70-79$ & & & & & & 70/99 (70.7\%) \\
\hline$\geq 80$ & & & & & & 29/99 (29.3\%) \\
\hline \multicolumn{7}{|l|}{ Sex } \\
\hline Male & & & & & & 60/99 (60.6\%) \\
\hline Female & & & & & & 39/99 (39.4\%) \\
\hline \multicolumn{7}{|c|}{$\begin{array}{l}\text { Pathological } \\
\text { status }^{*}\end{array}$} \\
\hline & NO & N1 & $\mathrm{N} 2 \mathrm{a}$ & $\mathrm{N} 2 \mathrm{~b}$ & N2c N3 & \\
\hline pT1 & 23 & 6 & 1 & 4 & & $34 / 98$ (34.7\%) \\
\hline pT2 & 24 & 4 & 1 & 3 & 1 & $34 / 98$ (34.7\%) \\
\hline pT3 & 3 & 4 & & 4 & & 11/98 (11.2\%) \\
\hline pT4 & 10 & 2 & 1 & 6 & & 19/98 (19.4\%) \\
\hline
\end{tabular}

Table II. Patient stratification accordingly to the lesion subsites.

\begin{tabular}{lc} 
& No. of patients (\%) \\
Oral cavity & $74 / 99(74.7 \%)$ \\
Gingiva & $9 / 74(12.2 \%)$ \\
Lips & $10 / 74(13.5 \%)$ \\
Tongue & $30 / 74(40.5 \%)$ \\
Oral mucosa & $16 / 74(21.6 \%)$ \\
Hard palate & $2 / 74(2.7 \%)$ \\
Floor of the mouth & $7 / 74(9.5 \%)$ \\
Oropharynx & $25 / 99(25.3 \%)$ \\
Anterior wall & $7 / 25(28.0 \%)$ \\
Lateral wall & $13 / 25(52.0 \%)$ \\
Superior wall & $5 / 25(20.0 \%)$ \\
\hline
\end{tabular}

soral procedures (TP), meaning mini-microinvasive surgeries as well as the non-surgical photodynamic therapy, in 14 of 99 patients (14.1\%), open neck resection without reconstruction (OR) in 59 of 99 patients (59.6\%) and open neck resection with reconstruction (ORR) in 26 of 99 patients (26.3\%).

Characteristics of the patient cohort are summarised in Table I, while stratification according to tumour site and sub-site is reported in Table II.

\section{Statistical analysis}

The length of time from the date of diagnosis to the date of death (overall survival, OS) or to the date of death for disease (disease-specific survival, DSS) was estimated 
using Kaplan-Meier curves. At the end of the study, the dates of last consultation for patients still alive were used for type-I censoring. Log-rank and Gehan-BreslowWilcoxon tests (for early events) were used to compare Kaplan-Meier estimates between groups (number of comorbidities, tumour site, type of surgery and postoperative complications). The CHAID (Chi-square Automatic Interaction Detection) method ${ }^{8}$ was used to detect the optimal subdivision to maximise the differences in response within the different variables.

Univariate regression with colinearity analysis was used to evaluate independent risk factors (e.g. age at the surgery $\geq 80^{9}$, gender, presence of comorbidities, tumour stage, type of surgery and duration of surgery) for development of perioperative and postoperative complications (within 30 days). Those significantly associated were included in a multivariable logistic regression model.

Kaplan-Meier curves, log-rank and Gehan-Breslow-Wilcoxon tests were performed with Graphpad Prism version 6.0e (GraphPad Software, San Diego, CA, USA), whereas CHAID analysis, univariate regression with colinearity analysis and multivariate logistic regression were performed with IBM $^{\circledR}$ SPSS $^{\circledR}$ Statistics version 23 (IBM Corp., Armonk, NY, USA). All analyses were considered statistically significant at $\mathrm{p}<0.05$.

\section{Results}

\section{Patient comorbidities}

Concomitant diseases were present in 69 of 99 (69.7\%) elderly patients, of whom 32 (32.3\%) were affected by multiple $(\geq 2)$ comorbidities. The most frequent were hypertension $(50.5 \%)$, cardiovascular disease $(25.2 \%)$, diabetes mellitus (19.2\%) and chronic obstructive pulmonary disease (COPD) (12.1\%). The severity of each comorbidity was scored and recorded according to the American Society of Anesthesiologists (ASA) physical status classification system ${ }^{410}$ (Table III).

Table III. Distribution of patients according to the American Society of Anesthesiologists (ASA) physical status classification system.

\section{No. of patients (\%)}

\begin{tabular}{lc} 
ASA & \\
1 & $9 / 97(9.3 \%)$ \\
2 & $34 / 97(35.1 \%)$ \\
3 & $43 / 97(44.3 \%)$ \\
4 & $10 / 97(10.3 \%)$ \\
5 & $1 / 97(1.0 \%)$ \\
\hline
\end{tabular}

\section{Surgery and postoperative morbidity}

The mean surgical time was $3.4 \pm 2.3 \mathrm{~h}$, ranging from 0.5 $\mathrm{h}$ to $10.5 \mathrm{~h}$ in patients aged $70-79$ years and from $0.5 \mathrm{~h}$ to $6.5 \mathrm{~h}$ in those $\geq 80$ years $(\mathrm{p}=0.156)$.

Amongst treated patients, 31 (14 OR and 17 ORR) were postoperatively transferred to the intensive care unit (ICU) where they resided for an average time between 1.6 days (70-79 years old) and 1.1 days (age $\geq 80$ years; $\mathrm{p}=0.675)$. Transfer to the ICU was decided by the anesthesiologist and was based on duration of surgery, preoperative ASA score and complications occurred during surgery. Generally, the mean length of hospitalisation was 21.0 days in 70-79 patients and 18.7 in those aged $\geq 80$ years $(\mathrm{p}=0.537)$. Patients were discharged when completely cured and autonomous in major activities (swallowing, breathing or cannula management).

Perioperative or postoperative complications affected 30 of 99 patients $(30.3 \%)$ of whom 21 of $70(30.0 \%)$ in the age range $70-79$ and 9 of $29(31.0 \%)$ in $\geq 80$ years $(\mathrm{p}=0.890)$.

Furthermore, stratifying patients for the type of surgery, no differences between groups were observed, although open techniques followed by reconstruction displayed a significantly higher incidence of complications than with other techniques in patients $70-79$ years old $(\mathrm{p}<0.05$, Fig. 1$)$.

In the 70-79 year group, 4 patients suffered systemic complications, 9 had local complications (mainly bleedings, fistulas and wound infections) and 5 developed both systemic and local complications. One patient suffered of multiple systemic complications, whereas 1 patient had 2 local complications. Two patients $(9.5 \%)$ died postoperatively. In the elderly aged $\geq 80,4$ patients developed a systemic complication, 1 patient had 2 systemic complications, whereas 4 patients suffered of local complication. One patient (11.1\%) died postoperatively (Table IV). Fi-

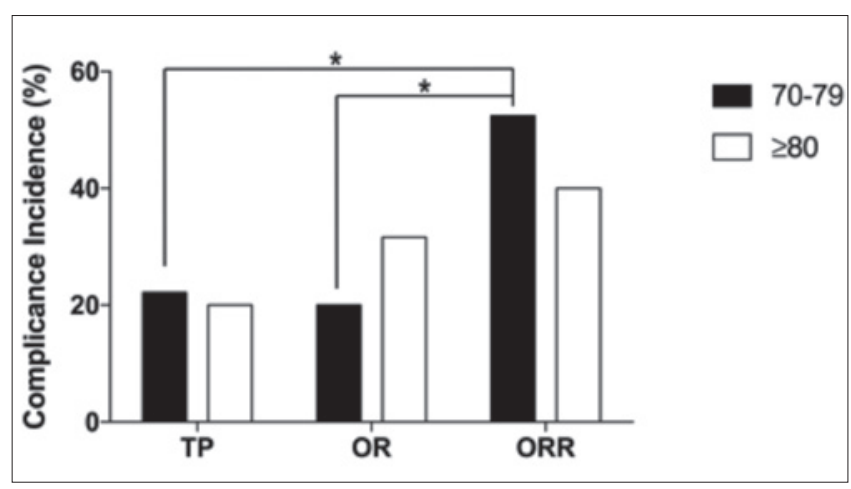

Fig. 1. Incidence of complications on patients treated by transoral procedure (TP), open neck resection (OR), or open neck resection with reconstruction (ORR). ${ }^{*}=p<0.05$. 
Table IV. Complications in patients.

\begin{tabular}{llcc} 
Complications & \multicolumn{2}{c}{ Number of events (\%) } \\
\cline { 2 - 3 } Local & Fistula & $3 / 21(14.3 \%)$ & $1 / 9(11.1 \%)$ \\
& Infections & $5 / 21(23.8 \%)$ & $0 / 9(0.0 \%)$ \\
& Haemorrhage & $2 / 21(9.5 \%)$ & $1 / 9(11.1 \%)$ \\
& Haematoma & $0 / 21(0.0 \%)$ & $0 / 9(0.0 \%)$ \\
& Necrosis & $1 / 21(4.8 \%)$ & $1 / 9(11.1 \%)$ \\
Systemic & Dehiscence & $3 / 21(14.3 \%)$ & $1 / 9(11.1 \%)$ \\
& Wound diastasis & $0 / 21(0.0 \%)$ & $1 / 9(11.1 \%)$ \\
& Seroma & $3 / 21(14.3 \%)$ & $0 / 9(0.0 \%)$ \\
& Pneumonia & $2 / 21(9.5 \%)$ & $2 / 9(22.2 \%)$ \\
& Cardiovascular* & $6 / 21(28.6 \%)$ & $1 / 9(11.1 \%)$ \\
& Psychiatric & $3 / 21(14.3 \%)$ & $1 / 9(11.1 \%)$ \\
& Death & $2 / 21(9.5 \%)$ & $1 / 9(11.1 \%)$ \\
& Nephropathy & $0 / 21(5.6 \%)$ & $0 / 9(0.0 \%)$ \\
& Cerebrovascular event & $1 / 21(4.8 \%)$ & $0 / 9(0.0 \%)$ \\
& Hyperglycaemia & $1 / 21(4.8 \%)$ & $1 / 9(11.1 \%)$ \\
& Sepsis & $0 / 21(0.0 \%)$ & $0 / 9(0.0 \%)$ \\
\hline
\end{tabular}

* Cardiovascular complications included acute miocardial infarction, arrhythmia, and cardiac arrest.

nally, 27 of 99 patients (27.3\%) underwent a second surgical procedure, whereas 9 of 99 patients $(9.1 \%)$ underwent a third salvage surgery.

Correlation of age, comorbidities, tumour site, type of surgery and complications with patient survival

Patients were followed for a mean period of 2.52 years (range 6 days - 9.3 years). At the last follow-up, 40 of 99 patients $(40.4 \%)$ were alive without disease, 26 died with disease $(26.3 \%)$ and 24 died for other reasons than head and neck cancer (24.2\%), whereas 8 were alive with disease $(8.1 \%)$. The remaining patient was lost to follow-up (1.0\%). At 5 years, overall survival (OS, 41.1\%) was not significantly affected by patient age at the surgery. In fact, OS was $49.9 \%$ in those $70-79$ years old and $18.4 \%$ in those aged $\geq 80$ years $(p=0.176$; for early events $p=0.433$ ), with $50 \%$ mortality at 3.6 and 1.7 years, respectively (Fig. 2A). Likewise, 5-year disease-specific survival (DSS, $66.1 \%$ ) was $64.4 \%$ in $70-79$ year old patients and $71.6 \%$ in the older ones (Fig. 2B; $\mathrm{p}=0.677$ ).

Furthermore, by stratifying chart data, we found that the presence of $\geq 2$ comorbidities at diagnosis significantly worsened life expectancy of patients $(\mathrm{p}<0.05)$. In these cases, OS was $23.9 \%$ (50\% mortality at 1.5 years), whereas it was $53.4 \%$ and $48.2 \%$ (50\% mortality at 3.9 years), respectively, in patients without or with 1 comorbidity (Fig. 3a). Otherwise, the anatomical localisation of the pathol-

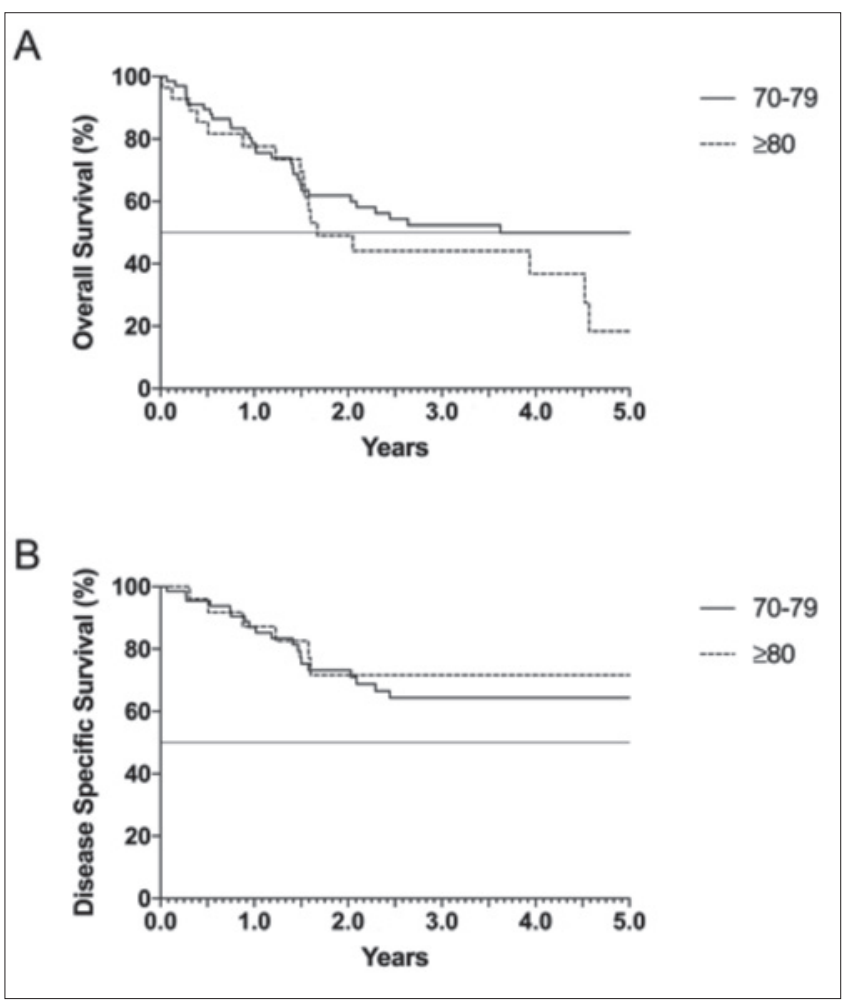

Fig. 2. Overall survival (A) and disease-specific survival (B) over a 5-year period in 99 patients with oral squamous cell carcinoma.

ogy had a marginal role ( $\mathrm{p}=0.510$, Fig. $3 b)$ : patients with tumours in the oral cavity had $45.5 \%$ OS $(50 \%$ mortality at 3.6 years), whereas those in which the pathology involved the oropharynx had $35.9 \%$ (50\% mortality at 2.4 years).

Regarding treatment, OS was affected by the presence of post-operative complications, although the choice of surgical technique did not play a direct role. In fact, 5-year OS of patients who experienced perioperative and postoperative complications was $31.2 \%$ (50\% mortality at 1.4 years), which is significantly lower ( $\mathrm{p}<0.05$; for early events $\mathrm{p}<0.01$ ) compared to $46.1 \%$ (50\% mortality at 4.5 years) of the other patients (Fig. 3c). Otherwise, patients treated by a more invasive ORR had 5-year OS of $41.0 \%$ vs. $42.3 \%$ and $52.4 \%$ of those treated by OR and TP, respectively $(\mathrm{p}=0.754)$ (Fig. 3d).

\section{Risk analysis on the development of complications}

Even if no variables evaluated displayed colinearity, age $\geq$ 80 years, gender, previous treatments, ASA physical status classification and duration of surgery did not show statistically significant correlations at univariate regression with the onset of perioperative and postoperative complications. On the contrary, they were correlated with the presence of concomitant diseases, tumour stage and type of surgery. 


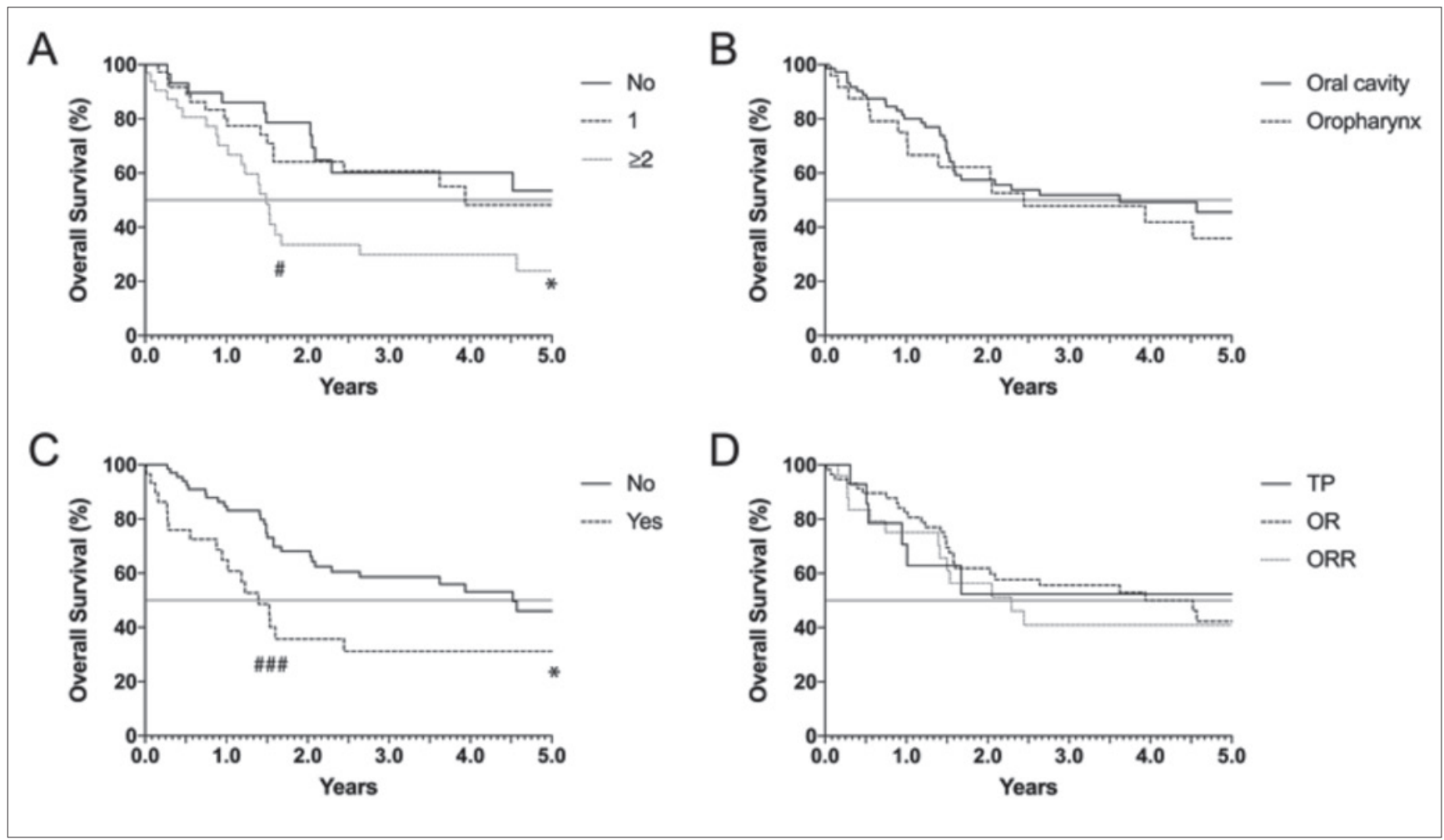

Fig. 3. Overall survival over a 5-year period of patients stratified for: presence of comorbidities at the diagnosis (A), tumour site (B), experience of peri- and/ or post-operative complications (C), or employed surgical procedure (D). * $p<0.05$ (Log-Rank test); \# $p<0.05$, \#\#\# $p<0.001$ (Gehan-Breslow-Wilcoxon test for early events). TP, transoral procedure; $\mathrm{OR}$, open neck resection; ORR, open neck resection with reconstruction.

In fact, patients affected by $\geq 2$ comorbidities were prone to develop complications with a risk of $53.1 \%$, which is significantly higher than those with 1 concomitant disease $(27.1 \%, \mathrm{p}<0.05)$ or without any comorbidities $(10 \%, \mathrm{p}<0.001)$. Similarly, patients who were diagnosed with early stage tumours had a lower risk ( $13.0 \%$ stage I and $16.7 \%$ stage II) to incur complications than those with advanced-stage disease $(43.8 \%$ stage III and $45.7 \%$ stage IV, $p<0.01)$. Finally, patients undergoing ORR had an higher risk $(\mathrm{p}<0.05)$ of developing complications $(50.0 \%)$ compared to those treated by OR $(23.7 \%)$ or TP $(21.4 \%)$.

Concomitant diseases, tumour stage and type of surgery were included together with the non-statistically significant age parameter in the following multivariate logistic regression model $(p<0.001$, Likelihood Ratio $\Lambda$ test):

$$
P=\frac{1}{1+e^{-[1.253+0.446(a)-0.741(b)+0.385(c)-2.887(d)-1.677(e)-2.070(f)-1.459(g)-0.313(h)]}}
$$

where: $(a)=$ patient aged $70-79 ;(b)=$ treatment by OR; $(c)=$ treatment by ORR; $(d)=$ absence of comorbidities; $(e)=$ presence of 1 comorbidity; $(f)=$ stage-I neoplasm; $(g)=$ stage-II neoplasm; $(h)$ stage-III neoplasm.

In the regression model (Table V), the type of surgery was not statistically significant for the predisposition to develop complications $(p=0.170)$. Their rate was determined accordingly, stratified for both concomitant diseases and pathology stage, and reported in Table VI.

\section{Discussion}

Worldwide, the progressively aging population makes treatment of elderly patients more frequent than in the past. Nevertheless, the elderly have the tendency to be often considered as a population that should be treated by less invasive/time-consuming procedures. Furthermore, full scientific agreement about not considering age by itself as a risk factor for incidence of surgical complications in the elderly it is still lacking ${ }^{11-18}$. Consequently, aggressive surgery on older patients has been generally infrequent until now ${ }^{19}$. However, it has been recently demonstrated for the treatment of laryngeal cancer that the employment of more invasive surgical procedures can also be adequate to treat older patients, albeit with some recommendations ${ }^{20}$. 
Table V. Multivariate regression analyses for the development of post-operative complications.

\begin{tabular}{lcccc} 
& $\begin{array}{c}-2 \text { Log } \\
(\boldsymbol{\Lambda})\end{array}$ & $\chi^{2}$ & df & P \\
Advanced stage & 67.085 & 9.684 & 3 & 0.021 \\
Comorbidities & 73.974 & 16.572 & 2 & 0.000 \\
Invasive surgical techniques & 60.948 & 3.547 & 2 & 0.170 \\
Age $\geq 80$ & 57.942 & 0.541 & 1 & 0.462 \\
\hline
\end{tabular}

$\Lambda$, likelihood ratio; $\chi^{2}$, chi squared; df, degrees of freedom.

Table VI. Complication risks (\%).

\begin{tabular}{cccccc}
\hline \multirow{3}{*}{ Tumour stage } & & \multicolumn{4}{c}{ No. of comorbidities } \\
& I & $1.8-5.4$ & 1 & $\geq 2$ \\
& II & $2.1-9.4$ & $6.8-25.9$ & $27.9-44.9$ \\
& III & 9.6 & $18.6-52.3$ & $55.0-85.5$ \\
& IV & $8.5-30.9$ & $23.8-60.0$ & $62.5-88.9$ \\
\hline
\end{tabular}

This finding could also be relevant for oral cancer. In the elderly, indeed, it is almost always (95\%) diagnosed as squamous cell carcinoma (OSCC) ${ }^{21}$ 22, a tumour histotype characterised by an intrinsic resistance to non-surgical approaches like radiotherapy and chemotherapy (including the newest proton therapy and "target therapy") ${ }^{23-25}$. The clinical evolution of OSCC has led to a rapid and strong decline in both life quality and expectancy, and includes pain, dysphagia, odynophagia, bleeding, fetor ex ore, teeth loss, inability to swallow and tumour externalisation from mouth and facial skin with consequent irreparable, permanent socially disfiguring impairment. The functional, cosmetic and psychological repercussions suffered by OSCC patients frequently result in significant burden for them, their families and society. Generally, their nutritional status is poor and depression is frequent, with important somatic problems that often cause social isolation.

In this context, surgery can be considered the only reliable approach and is, hence, the treatment of choice for all tumour stages ${ }^{2}$. Thus, the exclusion criteria of patients with diagnosis of OSCC from surgery (including more invasive techniques) should be finely defined, avoiding the a priori exclusion of older patients to more challenging therapeutic options because wrongly considered as frail ${ }^{10} 19$.

In this retrospective study, we considered a cohort of old (70-79 years) and very old ( $\geq 80$ years) patients ${ }^{9}$ affected by OSCC, in order to understand whether age represents per se a contraindication to treatment with open invasive surgery. Both old and very old populations were treated by one of three different approaches (transoral procedures, TP, open neck resection, OR, and open neck re- section with reconstruction, ORR), chosen according to tumour stage and site, as well as comorbidities. The distribution of patients to surgical techniques was homogeneous between the two groups. Likewise, no differences were detected among groups after comparison between surgical time, number of ICU and hospitalisation days and incidence of complications. No significant differences were detected in terms of overall survival (OS) at 5 years from surgery, though a poorer $18.4 \%$ was detected in $\geq 80$ year old patients vs $49.9 \%$ of those $70-79$ years $(\mathrm{p}=0.176)$. This non-significant difference was likely due to physiological instead of pathological causes, since during the same period disease-specific survival (DSS) was at some extent better $(71.6 \%)$ in $\geq 80$ years than in those $70-79(64.4 \%, \mathrm{p}=0.677)$ years. This finding is further corroborated if we consider younger cohorts. In fact, following 489 patients (median age $=62$ ) affected by oral tumours (40\% in advanced stage), Rogers and co-workers 26 achieved $74 \%$ DSS after 5 years from surgical treatment. Furthermore, they reviewed the results from other cohorts in which the 5-year DSS varied from $49 \%$ to $84 \%$. Combining the data, we can deduce an overall cohort of 805 patients with a DSS of $73.4 \%$ that is completely superimposable $(p=0.871)$ with our full-cohort DSS $(66.1 \%)$. By patient stratification, we detected that OS was affected by both comorbidities at diagnosis and post-operative complications. Patients with $\geq 2$ comorbidities had $23.9 \%$ OS vs. $\sim 50 \%$ seen in the others. Similarly, patients who developed complications had $31.2 \%$ OS compared to the $46.1 \%$ of those who did not $(\mathrm{p}<0.05)$, although the phenomenon was more evident in the first post-operative years $(\mathrm{p}<0.001)$. Otherwise, tumour localisation as well as the choice of surgical approach did not have an apparent role in OS, even if we detected a higher incidence of complications $(p<0.05)$ in those $70-79$ years undergoing a more extended ORR approach. As recently stated by Grammatica and coworkers, reconstruction still remains a complex procedure that affects the development of both local and systemic perioperative complications ${ }^{27}$.

As a confirmatory result, at univariate analysis the factors involved in the development of complications for our patient cohort were the presence of comorbidities, tumour stage and type of surgery employed, rapidly discharging any implication role of age, gender, previous treatments, ASA score and duration of surgical treatment. Nevertheless, at multivariate analysis, the role of each surgical approach became statistically negligible, highlighting a predominant involvement of tumour stage and above all the presence of concomitant diseases. Patients without comorbidities had a small to moderate risk in developing post-operative complications, even facing more ad- 
vanced pathologies (stage III/IV, 8.5-30.9\% risk). At any rate, the risk is already increased for patients facing very early stage tumours, but with $\geq 2$ concomitant diseases (I/ II, $17.4-50.3 \%$ risk).

As final digression, we would conclude that no differences in terms of functional outcomes (oral diet, speech intelligibility, and mouth opening) were detected among old and very old patients. Even if in our cohort much chart data did not report functional outcomes and for this reason results can only be considered as preliminary, they seem to be in accordance with the results of Nao and co-workers ${ }^{28}$, although they compared younger patients ( $<70$ vs $\geq 70$ years).

\section{Conclusions}

Up to now, it is widely accepted that elderly OSCC patients could not be treated with the standard of care because of medical prejudices related to advanced age. Nevertheless, our findings support the growing acceptance that chronological age alone should not be a sufficient contraindication for aggressive surgical therapy for OSCC. Instead, the presence of comorbidities at diagnosis might play a pivotal role in the choice of the more appropriate treatment of elderly patients. In multivariate analysis, indeed, comorbidities correlated with the development of postsurgical complications, thus foreclosing access to many treatment options. For these reasons, elderly patients affected by OSCC are undoubtedly delicate surgical candidates and accurate selection based on our results prior to surgery for curative intentions is mandatory.

Sharing and improving our knowledge in elderly patients is helpful for all clinicians due to aging of the population, with the aim to improve the quality of life and overall survival in elderly patients.

\section{Acknowledgements}

We thank Dr. F. Di Scipio for providing critical and linguistic assistance.

\section{Conflict of interest statement}

None declared.

\section{References}

1 Ferlay J, Soerjomataram I, Ervik M, et al. GLOBOCAN 2012 v1.0. Cancer Incidence and Mortality Worldwide: IARC CancerBase No. 11 [Internet]. In. Lyon, France: International Agency for Research on Cancer, 2013.

2 National Comprehensive Cancer Network. NCCN Clinical Practice Guidelines in Oncology. Head and Neck Cancers (Version 1.2017), 2017.
3 Piccirillo JF, Vlahiotis A, Barrett LB, et al. The changing prevalence of comorbidity across the age spectrum. Crit Rev Oncol Hematol 2008;67:124-32.

4 American Society of Anesthesiologists (ASA). New classification of physical status. Anesthesiology 1963;24:111.

5 Kowalski LP, Alcantara PS, Magrin J, et al. A case-control study on complications and survival in elderly patients undergoing major head and neck surgery. Am J Surg 1994;168:485-90.

6 Moye VA, Chandramouleeswaran S, Zhao N, et al. Elderly patients with squamous cell carcinoma of the head and neck and the benefit of multimodality therapy. Oncologist 2015;20:159-65.

7 Peters TT, Post SF, van Dijk BA, et al. Free flap reconstruction for head and neck cancer can be safely performed in both young and elderly patients after careful patient selection. Eur Arch Otorhinolaryngol 2015;272:2999-3005.

8 Kass GV. An exploratory technique for investigating large quantities of categorical data. J R Stat Soc Ser C Appl Stat 1980;29:119-27.

9 Howard MA, Cordeiro PG, Disa J, et al. Free tissue transfer in the elderly: incidence of perioperative complications following microsurgical reconstruction of 197 septuagenarians and octogenarians. Plast Reconstr Surg 2005;116:1659-68; discussion 1669-71.

10 Audisio RA, Ramesh H, Longo WE, et al. Preoperative assessment of surgical risk in oncogeriatric patients. Oncologist 2005;10:262-8.

11 De Melo GM, Ribeiro KC, Kowalski LP, et al. Risk factors for postoperative complications in oral cancer and their prognostic implications. Arch Otolaryngol Head Neck Surg 2001;127:828-33.

12 Fang QG, Shi S, Li M, et al. Free flap reconstruction versus non-free flap reconstruction in treating elderly patients with advanced oral cancer. J Oral Maxillofac Surg 2014;72:1420-4.

13 Farquharson SM, Gupta R, Heald RJ, et al. Surgical decisions in the elderly: the importance of biological age. $\mathrm{J} \mathrm{R}$ Soc Med 2001;94:232-5.

14 Peters TT, van Dijk BA, Roodenburg JL, et al. Relation between age, comorbidity, and complications in patients undergoing major surgery for head and neck cancer. Ann Surg Oncol 2014;21:963-70.

15 Sanabria A, Carvalho AL, Melo RL, et al. Predictive factors for complications in elderly patients who underwent head and neck oncologic surgery. Head Neck 2008;30:170-7.

16 Spyropoulou GA, Jeng SF, Hsieh CH, et al. Microsurgical reconstruction for head and neck cancer in elderly patients. J Reconstr Microsurg 2014;30:91-6.

17 Teymoortash A, Kunzmann J, Daniel H, et al. [Clinical aspects of transoral laser surgery and neck dissection for oro- and hypopharyngeal cancer in elderly patients]. HNO 2014;62:342-9.

18 Zabrodsky M, Calabrese L, Tosoni A, et al. Major surgery in elderly head and neck cancer patients: immediate and long- 
term surgical results and complication rates. Surg Oncol 2004;13:249-55.

19 Teymoortash A, Ferlito A, Halmos GB. Treatment in elderly patients with head and neck cancer: a challenging dilemma. HNO 2016;64:217-20.

20 Crosetti E, Caracciolo A, Molteni G, et al. Unravelling the risk factors that underlie laryngeal surgery in elderly. Acta Otorhinolaryngol Ital 2016;36:185-93.

21 Koch WM, Patel H, Brennan J, et al. Squamous cell carcinoma of the head and neck in the elderly. Arch Otolaryngol Head Neck Surg 1995;121:262-5.

22 Pignon T, Horiot JC, Van den Bogaert W, et al. No age limit for radical radiotherapy in head and neck tumours. Eur $\mathrm{J}$ Cancer 1996;32A:2075-81.

23 Chinn SB, Myers JN. Oral cavity carcinoma: current management, controversies, and future directions. J Clin Oncol 2015;33:3269-76.
24 Belcher R, Hayes K, Fedewa S, et al. Current treatment of head and neck squamous cell cancer. J Surg Oncol 2014;110:551-74.

25 Georges P, Rajagopalan K, Leon C, et al. Chemotherapy advances in locally advanced head and neck cancer. World $\mathrm{J}$ Clin Oncol 2014;5:966-72.

26 Rogers SN, Brown JS, Woolgar JA, et al. Survival following primary surgery for oral cancer. Oral Oncol 2009;45:201-11.

27 Grammatica A, Piazza C, Paderno A, et al. Free flaps in head and neck reconstruction after oncologic surgery: expected outcomes in the elderly. Otolaryngol Head Neck Surg 2015;152:796-802.

28 Nao EE, Dassonville O, Poissonnet G, et al. Ablative surgery and free flap reconstruction for elderly patients with oral or oropharyngeal cancer: oncologic and functional outcomes. Acta Otolaryngol 2011;131:1104-9.

Received: November 18, 2016 - Accepted: September 29, 2017

Address for correspondence: Erika Crosetti, Head and Neck Oncology Service, Oncology Dept., University of Turin - IRCCS FPO Candiolo Cancer Institute, strada Provinciale $142 \mathrm{~km} \mathrm{3.95,} 10060$ Candiolo (TO), Italy. Tel. +39 011 9933111. E-mail: erikacro73@ yahoo.com 